\title{
Aflatoxins in Mozambique: Etiology, Epidemiology and Control
}

\author{
Edgar Cambaza ${ }^{1,2, *(\mathbb{D})}$, Shigenobu Koseki ${ }^{1}$ and Shuso Kawamura ${ }^{1}$ \\ 1 Laboratory of Food Process Engineering, Graduate School of Agriculture, Hokkaido University, \\ Sapporo 060-0808, Japan; koseki@bpe.agr.hokudai.ac.jp (S.K.); shuso@bpe.agr.hokudai.ac.jp (S.K.) \\ 2 Department of Biological Sciences, Faculty of Sciences, Eduardo Mondlane University, Av. Julius Nyerere, nr. \\ 3453 Maputo, Moçambique \\ * Correspondence: accademus@protonmail.com; Tel.: +81-80-2876-1106
}

Received: 26 May 2018; Accepted: 18 June 2018; Published: 21 June 2018

check for updates

\begin{abstract}
Mozambique is endemic to aflatoxigenic Aspergillus but the country has to heavily rely on foreign research to deduce what is happening locally. There is some information produced by local scholars and institutions but it needs to be "tied" together. This review briefly synthetizes the country's major findings in relation to the toxin's etiology, epidemiology, detection and control, discussing and meta-analyzing them as far as they allow. The causes and commodities affected are the same as in most tropical countries; the toxin is widespread and the level of exposure is high. Regarding the control, it is still marginal but some institutions have driven efforts in this direction. Learning from other countries is still the best approach to take, as the solutions are probably the same for most places.
\end{abstract}

Keywords: aflatoxins; Mozambique; etiology; epidemiology; control

\section{Introduction}

The aflatoxins $\mathrm{B}_{1}\left(\mathrm{AFB}_{1}\right)$ and $\mathrm{G}_{1}\left(\mathrm{AFG}_{1}\right)$ have been found in Mozambican commodities, especially groundnuts and maize [1,2]. However, the information is clustered in sporadic, scarcely related reports, and there is very low awareness outside academic circles. Warth et al. [2] mentioned the urge for comprehensive data on mycotoxins. There is a review by Ferrão et al. [3] about mycotoxins in Southern Africa. It is introductory and generic in content, probably because it explores a very broad topic. There is little research about $\mathrm{AFB}_{1}$ because its surveillance and control are generally costly. Indeed, Harmsen et al. [4] presented an interview with David Mariote, Eduardo Mulima and Miguel Magalhães, senior plant breeders from the National Institute of Agricultural Research, stating a low demand for $\mathrm{AFB}_{1}$ analysis in Nampula province, not compensating the investment for the equipment. But the authors expect an increase in demand for such kind of analysis in a near future.

Organized information is the key for a better understanding. The isolated clusters of scientific production need to be tied in a concise document for the current and future generations. Well-mapped information on aflatoxins in Mozambique will show where are the gaps to be filled and the next steps for the academia, industry and civil society. It also brings contradictions and unclear parts of the research to the surface. For example, most authors make people perceive groundnuts as the biggest and sometimes sole source of aflatoxins [1,5], while Warth et al. [2] found more in maize than in groundnuts. There might be some bias just because most $\mathrm{AFB}_{1}$ research is on groundnuts because of trade requests.

This paper aims to present the causes, distribution and control of aflatoxin exposure in Mozambique according to studies performed in the country so far. 


\section{Major Aflatoxin Studies in Mozambique}

Part of this review is based on a meta-analysis of Mozambican reports published from 1985 to 2017 (Table 1). The time gaps were always over 5 years and the samples varied considerably. There are differences in the way the data was collected and analyzed. For instance, not all registered the prevalence of aflatoxins, most did not distinguish the type of aflatoxins detected, and some presented the results in average and others median. Yet, the results allow some comparisons.

Table 1. Summary of the major aflatoxin studies in Mozambique and their findings.

\begin{tabular}{|c|c|c|c|c|c|c|}
\hline Author & Year & Product & $\begin{array}{l}\text { Sample } \\
\text { Size }(n)\end{array}$ & $\begin{array}{c}\text { Prevalence } \\
(\%)\end{array}$ & $\begin{array}{c}\text { Average } \\
(\mu \mathrm{g} / \mathrm{kg})\end{array}$ & $\begin{array}{c}\text { Median } \\
(\mu \mathrm{g} / \mathrm{kg})\end{array}$ \\
\hline \multirow{13}{*}{ Casadei, E. [6] } & \multirow{13}{*}{1980} & Beans & 54 & 17.0 & - & 6.0 \\
\hline & & Beer & 15 & 93.0 & 1.1 & 1.0 \\
\hline & & Cassava flour & 12 & 25.0 & 28.1 & 40.0 \\
\hline & & Corn & 32 & 87.0 & 22.6 & 17.0 \\
\hline & & Corn flour & 31 & 52.0 & 18.3 & 10.0 \\
\hline & & Dry cassava & 10 & 10.0 & - & - \\
\hline & & Forage & 25 & 32.0 & - & 50.0 \\
\hline & & Groundnut & 37 & 92.0 & - & 49.0 \\
\hline & & Maize & 18 & 67.0 & 22.0 & 21.0 \\
\hline & & Rice & 56 & 63.0 & 16.2 & 11.0 \\
\hline & & Sesame & 6 & 33.0 & - & - \\
\hline & & Sorghum & 11 & 9.0 & 6.5 & 5.0 \\
\hline & & Wheat & 13 & 22.0 & 8.5 & 9.0 \\
\hline \multirow{2}{*}{ Van Rensburg, S.J. et al. [7] } & \multirow{2}{*}{1985} & Groundnut & 153 & - & 1036.0 & - \\
\hline & & Maize & 168 & - & 2.4 & - \\
\hline Van Wyk, P. et al. [1] & 1999 & Groundnut & 4 & 8.3 & - & 92.6 \\
\hline \multirow{4}{*}{ Warth, B. et al. [2] } & \multirow{4}{*}{2012} & Feed waste & 1 & - & - & 433.0 \\
\hline & & Groundnut & 23 & - & - & 3.4 \\
\hline & & Maize & 13 & - & - & 69.9 \\
\hline & & Millet & 2 & - & - & 4.0 \\
\hline \multirow[t]{2}{*}{ Sineque, A.R. et al. [8] } & \multirow[t]{2}{*}{2017} & $\begin{array}{l}\text { Chicken } \\
\text { gizzard }\end{array}$ & 80 & 13.8 & 1.1 & - \\
\hline & & Chicken liver & 100 & 39.0 & 1.7 & - \\
\hline
\end{tabular}

Beer showed the highest prevalence $(93 \%)$ but its aflatoxin levels are very low and safe for human consumption if compared to the limit recommended by Codex Alimentarius (10 $\mu \mathrm{g} / \mathrm{kg})$ [9]. Grains, cassava and derivatives require more attention in regards to toxicity, but groundnut has been the most concerning product. Forage and feed waste showed high levels of contamination in comparison with most products but they are not a public health concern because they are not meant for human consumption.

However, the limit recommended by the codex is provisional and it was set for peanuts. Yet, it is the best reference available for Mozambique as a member of the World Health Organization and the Food and Agriculture Organization of the United Nations, since the country has no specific regulations for mycotoxin contamination.

\section{Etiology and Commodities}

\subsection{Etiology}

In Mozambique, aflatoxins are produced by the same molds found in other countries: A. flavus and A. parasiticus [2,10], found in Nampula, Tete and Zambézia provinces. Augusto et al. [10] mentioned the same fungi, stressing A. flavus L-strain and A. parasiticus as the most abundant in the center and north of the country, but they also found A. flavus S-strain and A. tamarii. Warth et al. [2] found $\mathrm{AFB}_{1}$ in their food and feed collected in Nampula province, and from that they deducted the presence of A. parasiticus or A. flavus Group II.

Most studies from Mozambique are focused on $\mathrm{AFB}_{1}$ or do not distinguish aflatoxins. Few, such as the surveys mentioned by Baquete and Freire [11] and van Wyk et al. [1], also detected $\mathrm{AFB}_{2}, \mathrm{AFG}_{1}$ and $\mathrm{AFG}_{2}$ in Mozambican food. Only van Wyk et al. [1] mentioned the province where their samples came 
from (Nampula). The lack of depth in most studies is probably due to the need of rapid screenings. Despite the differences in toxicity, all the different aflatoxins are harmful and should be avoided.

\subsection{Commodities}

Several commodities have aflatoxins. The hosts can range from cotton, wheat and sorghum [12,13] to rice [14] and other produces. Warth et al. [2] added millet, feed and feed waste to the list. Virtually all sorts of cereals, grains and their derivatives are vulnerable to contamination. Cassava has also received some attention, though very few times $[6,15,16]$. There is a beer made from fresh cassava [3], but it was never analyzed in Mozambique, despite the suspicions. However, most studies in Mozambique are focused on maize and groundnut. These crops are better known for their high commercial value and a history of confirmed cases of aflatoxin contamination. Yet, there is always a need to better clarify the data on the toxin's prevalence in maize and groundnut in Mozambique [17].

The intense focus on only two or three major crops ends up neglecting many more. Casadei [6] reports aflatoxin contamination in rice, sorghum, maize, sweet corn, corn flour, wheat, beans, groundnuts, sesame, dry cassava, cassava flour, forage, beer and other commodities in his book on Mozambican water and foods. Baquete and Freire [11] said there were more commodities, being 17 in total. All but sorghum, sesame, dry cassava and beer were contaminated by over $5 \mu \mathrm{g} / \mathrm{kg}$. Among them, maize, corn products, rice, groundnuts and beer had over $50 \%$ of samples contaminated, and from these, groundnuts had the highest median aflatoxin content $(49 \mu \mathrm{g} / \mathrm{kg})$. These observations stress groundnuts as the prime source of aflatoxins and maize among the majority. Yet, the remaining commodities should not be underestimated.

The publications above might be outdated because the country's economic situation is not the same now [18]. Also, many more people have unprecedented access to higher levels of education and information nowadays. It would not be unrealistic to assume nothing has evolved since then. Nonetheless, Augusto et al. [10] also found more recently higher levels in groundnuts in relation to maize. His study was only in the country's center and north but included Zambézia and Nampula provinces, both forming a hot spot of Aspergillus infestation and aflatoxin contamination. However, Warth et al. [2] also collected samples from Nampula but found a higher prevalence (46\%) and levels in maize compared to groundnuts $(14 \%)$. They went even further, detecting values of aflatoxins B, G and other mycotoxins, all at higher levels in maize samples. Their differences might be attributable to the sampling process. Warth et al. [2] obtained the food from different sources including farmers and markets, while Augusto et al. [10] worked with soil samples and food collected from experimental fields. Maybe the food from the market had already received some treatment such as selection of non-moldy specimens. The same applies to farmers, more concentrated on the production rather than research. Some additional factors such as different seasons and storage can be considered.

Studies on cassava are very discrepant. Mota and Lourenço [15] found high aflatoxin levels (up to $4.61 \times 10^{-3} \mu \mathrm{g} / \mathrm{kg}$ ), Casadei [6] found moderated and Essers and Nout [16] nothing at all. More recent evidence from two neighboring countries, Zambia and Malawi, points towards low levels [19]. There are some distinct variables to consider: the studies were done at different decades, covered different areas, although they all covered Nampula province, and were performed for different purposes. Casadei [6] described the only the only study intentionally designed to search for aflatoxins. The others were more concerned about another toxins as harmful: cyanogenic compounds. This might have led the authors not to analyze more deeply the aflatoxins once they got the answer they were trying to find. It is likely that effort to reduce the cyanogenic compounds also ended up somehow decreasing the aflatoxin content in cassava. Anyway, aflatoxin levels in cassava and derivatives shall be regarded as inconclusive so far but it should be taken more seriously as some evidence pointed to very high levels.

There is research on feed, mostly for poultry. Mondlane et al. [20] dedicated a study to mold infestation and $\mathrm{AFB}_{1}$, and Walker et al. [21] included feedstuff and its waste in their study on multiple toxins and commodities. The former author analyzed 69 samples from four factories, from which $65 \%$ 
were infested by A. flavus and contaminated. In some cases, the values exceeded the recommendations by the Codex Alimentarius (10 $\mu \mathrm{g} / \mathrm{kg}$ ). Walker et al. [21] found similar results, with $60 \%$ of the samples heavily contaminated. This should be expected because the food unfit for human consumption is primarily fed to animals [22]. In the latter study, the waste products were extremely contaminated, but it is understandable. The waste probably includes peel and other surface parts where the molds are more likely to grow, and probably there is no special treatment to reduce infestation and contamination in these parts. This actually poses a problem if it is used to make compost, for example, because the molds can be rechanneled to the fields. The most important to conclude from both studies is their confirmation of high levels of aflatoxins in feed and its risks for animal health.

The study conducted by Sineque et al. [8] is one example of what happens when contaminated feedstuff is given to animals. They found $\mathrm{AFB}_{1}$ in chicken livers and gizzards from abattoirs in Maputo. The levels were low; nonetheless, they also demonstrated that toxins actually make into these organs and remain there for some time. Human exposure to mycotoxins is not only a function of the levels in food but also the frequency and quantity consumed. High levels of $\mathrm{AFB}_{1}$ are probably the cause of acute jaundice, but hepatic cancer results from a long-term effect of the aflatoxins, and it might not require high concentrations of such chemicals. It would be wise analyze the dynamics of the toxic influence on the onset of primary liver cancer.

Baquete and Freire [11] mentioned a program investigating if contaminated food is resulting in the presence of $\mathrm{AFM}_{1}$. However, there are no further records of such events readily available. It might have been cancelled and/or its results were inconclusive. Indeed, Ferrão et al. [3] implied the lack of such information and recommended the studies because studies in Germany demonstrated its plausibility.

\subsection{Circumstances of Contamination}

There is comprehensive international literature on how the molds make into the food and what facilitates it. However, it has been hard to directly relate the level of mold infestation with mycotoxin production [23]. Still, genetic features such as the species and strain, and environmental such as temperature and humidity, have been effectively associated with toxin contamination. Most studies end up analyzing that indirectly as they describe the study area or sampling conditions, and some are designed exactly to analyze such factors. Thus, there is information on that, though the role of each factor would be better understood if properly modeled.

Ferrão et al. [3] said in Mozambique the exposure to high aflatoxin levels results from intake of maize, cassava, peanuts and other oilseeds. This information agrees with most of the available data but it is probably due to bias, as previously stated. Aflatoxins are found in several commodities [6,11]. Commercial and political forces are behind the abundance of knowledge about just a few crops. That is why only old surveys covered a larger variety of foods. Yet, cash crops are indeed a good starting point to examine the situation in Mozambique.

Natural causes can highly influence the contamination. Mozambique has a typical tropical climate and it favors the growth of Aspergillus in the crops [22]. Moreover, van Wyk et al. [1] said that drought and temperature stress, combined with soil pests, parasites and diseases during the pre-harvest, play a major role on damaging the grain and allowing the mold to invade. There are further noteworthy findings by Augusto et al. [10], based on humidity, temperature and altitude. He found high infestation in "hot, humid and low to medium altitude (50-600 m)" and low in "wet, high altitude (>1000 m)", not mattering which crop. It is reasonable, as one should expect less biodiversity as the altitude increases.

Though nature cannot be defied, crop handling can highly influence the level of infestation and contamination. According to Zuza et al. [5], the combination of adverse weather and inadequate methods for harvest and post-harvest impact of the contamination. The farmers, traders, processors and exporters need to be careful during harvest, drying or curing, and storing during post-harvest [1]. It is important to control the harvest time, because delays expose the crops to mold infections and 
aflatoxin contamination [5,24]. Also, Harmsen et al. [4] recommend the handlers not to store food in compartments too wet or in plastic bags.

The path to aflatoxin intake has four major components: Aspergillus infestation, aflatoxin contamination, consumers' exposure and intake. The first two were already described above. The following also deserves attention, although there is little updated and consistent information. Another thing to consider is the overall effect of the aflatoxins, not just the consumption. Ultimately, the consequences matter the most, in this case acute jaundice and hepatocellular carcinoma.

Van Rensburg et al. [7] and related studies were partially based on the analysis of food prepared by the rural population in Inhambane province. Since high levels of toxins were found, one can imply that the handling of the food was not safe enough to prevent such quantity in the diet. Exposure was daily for most foods and drinks. If hepatocellular carcinoma (HCC) depends on the combination of aflatoxins and hepatitis B (HBV), the causes of hepatitis also take part in this analysis. HBV is a sexually transmitted disease or, in general, transmitted through body fluids. Risk factors in Mozambique shall be seen as amplifiers for aflatoxin effects.

The last factor highly influences the exposure is possibly the most relevant: the food insecurity. According to Casadei [6], the destruction of contaminated foods and feeds was highly discouraged just after the independence. There was a civil war compromising the production, political feuds certainly limiting trade between Mozambique and South Africa and Rhodesia (now Zambia and Zimbabwe), extreme cases of draught, among numerous other challenges for the new government. The food could not be destroyed because there was a shortage. Instead, it was usually cleaned, diluted in non-contaminated stocks or sent to oil refineries out of hope to reduce contamination. The food insecurity still conflicts safety issues. Indeed, eradicating hunger and poverty are arguably the hottest global topics and priorities for the United Nations (UN) $[25,26]$.

The circumstances influencing aflatoxin intake in Mozambique form a complex network of challenges to be addressed, some natural and technical, and other social. The natural and technical just require some expertise, resources and technology. The social aspects are more delicate and sensitive. How to effectively change people's habits and traditions? How to reduce production if there is hunger internally and international incentive to mitigate food insecurity? Figure 1 shows a summary of what was covered in the present section, with some modifications.

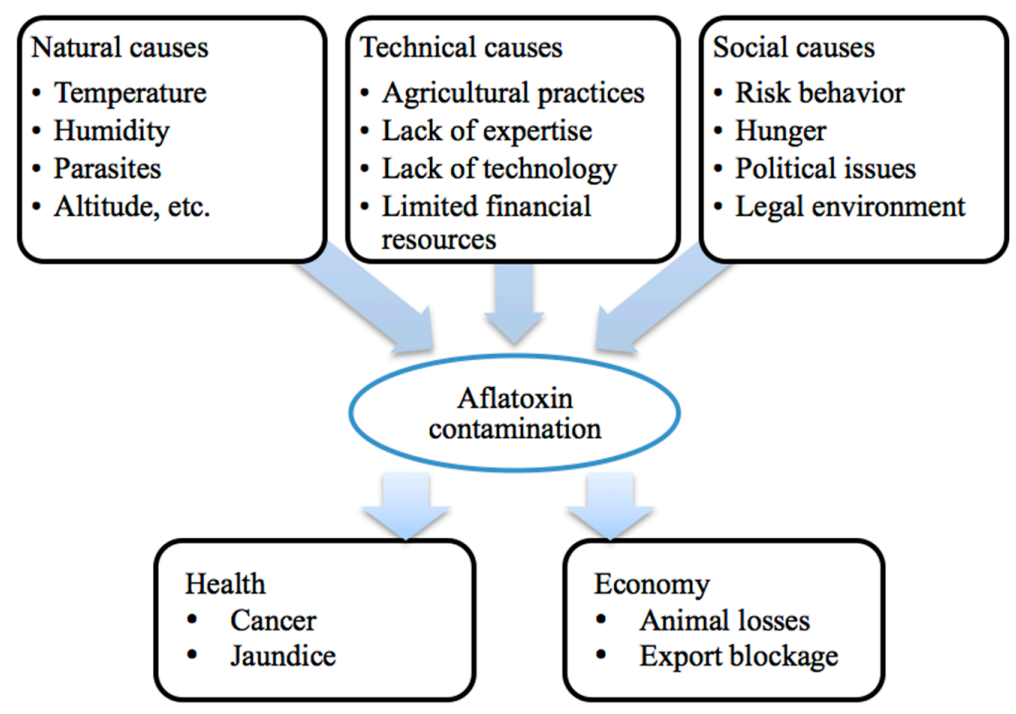

Figure 1. Causes and impact of aflatoxin contamination.

Where along the food chain have the aflatoxins been found in Mozambique? Figure 2 is a meta-analysis showing where most samples were drawn from. Yet, it is important to note that different samples were considered separately, even if collected at the same time for the same study. 


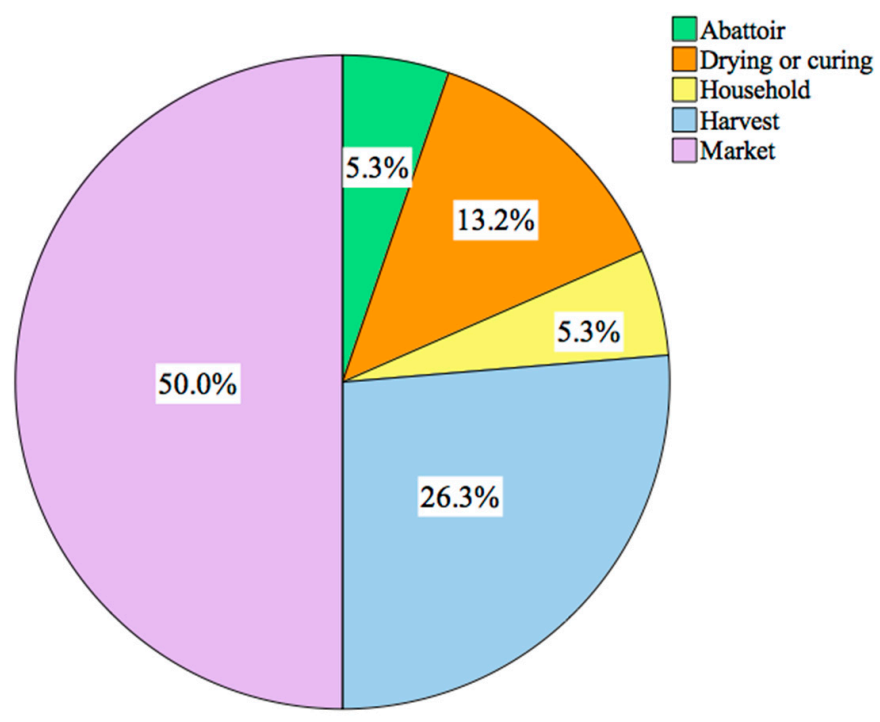

Figure 2. Pie chart showing the context in which the samples were collected in most studies. The samples included agricultural crops, chicken livers and gizzards. These studies were carried from 1985 to 2017 and included in total 934 samples. Based on Casadei [6], Van Rensburg et al. [7], van Wyk et al. [1], Warth et al. [2] and Sineque et al. [8].

The majority of samples were purchased in farmers' markets and shops, probably because at this stage the products are considered ready for domestic consumption. Samples from abattoirs were also already approved for commercialization [8]. Furthermore, it is likewise easier to get samples in this way, with no need of permission from some ethics committee if the researchers can afford the price. Additional samples were collected during harvest, post-harvest; certainly in experimental fields. The samples from households shall be regarded as the ultimate evidence of exposure, though these were related to the medical studies by Van Rensburg et al. [7] and possibly outdated.

The quantity of samples contaminated seems to increase as they move from farm to market (Figure 3).

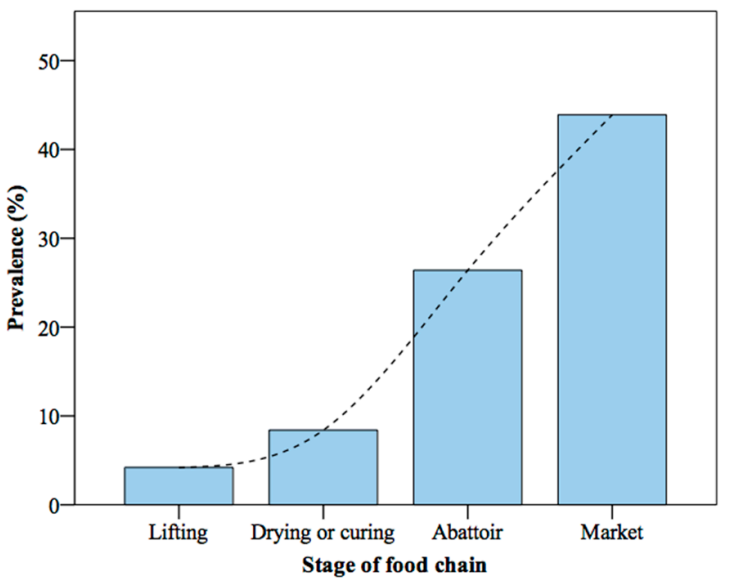

(a)

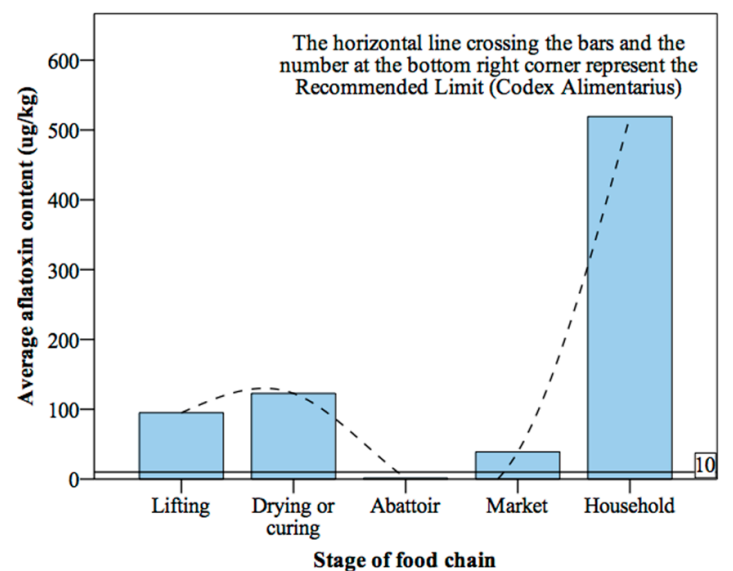

(b)

Figure 3. The prevalence (a) and level (b) of aflatoxin contamination in the major stages of the food production chain. The provisional limit for aflatoxin levels recommended Codex Alimentarius is $10 \mu \mathrm{g} / \mathrm{kg}$. Based on Casadei [6], Van Rensburg et al. [7], van Wyk et al. [1], Warth et al. [2] and Sineque et al. [8]. These studies were carried from 1985 to 2017 and included in total 934 samples including agricultural crops, chicken livers and gizzards. 
This is probably in part due to pest management and the existence of natural enemies in the farm. Furthermore, the product is mixed during transportation and storage, increasing the odds of cross-contamination. However, the level of contamination per sample showed a different trend. It appeared to be the lowest the factory and market but abruptly increased in the households.

The factory and market are expected to have lower mold infestation and aflatoxin levels in their commodities because they select and try to offer good quality products, as they are prone to be more consumer-driven. The households, however, frequently do not possess the resources and sometimes level of concern to keep up with the high food safety standards as the companies. From these observations, we can conclude that consumers have the most quantitatively and qualitatively contaminated food and focus to control aflatoxin should be at that end of the food production chain.

\section{Geographic Distribution of Aflatoxins and Related Diseases}

\subsection{Geographic Distribution}

By the turkey $X$ disease episode [27], Brazil can be presumed as an early hotspot of aflatoxicosis. Ozturk [28] mentioned African countries such as Mozambique, Uganda, Kenya, Senegal, Swaziland, Nigeria, and Asian, such as China, Thailand and Philippines. Now, there is a wide literature from virtually the entire world [3,29], especially after the Kenyan incident and initiatives from the International Agency for Research on Cancer (IARC) [30] and Codex Alimentarius Commission [9].

Figure 4 shows where aflatoxins were detected in Mozambique and in which commodities.

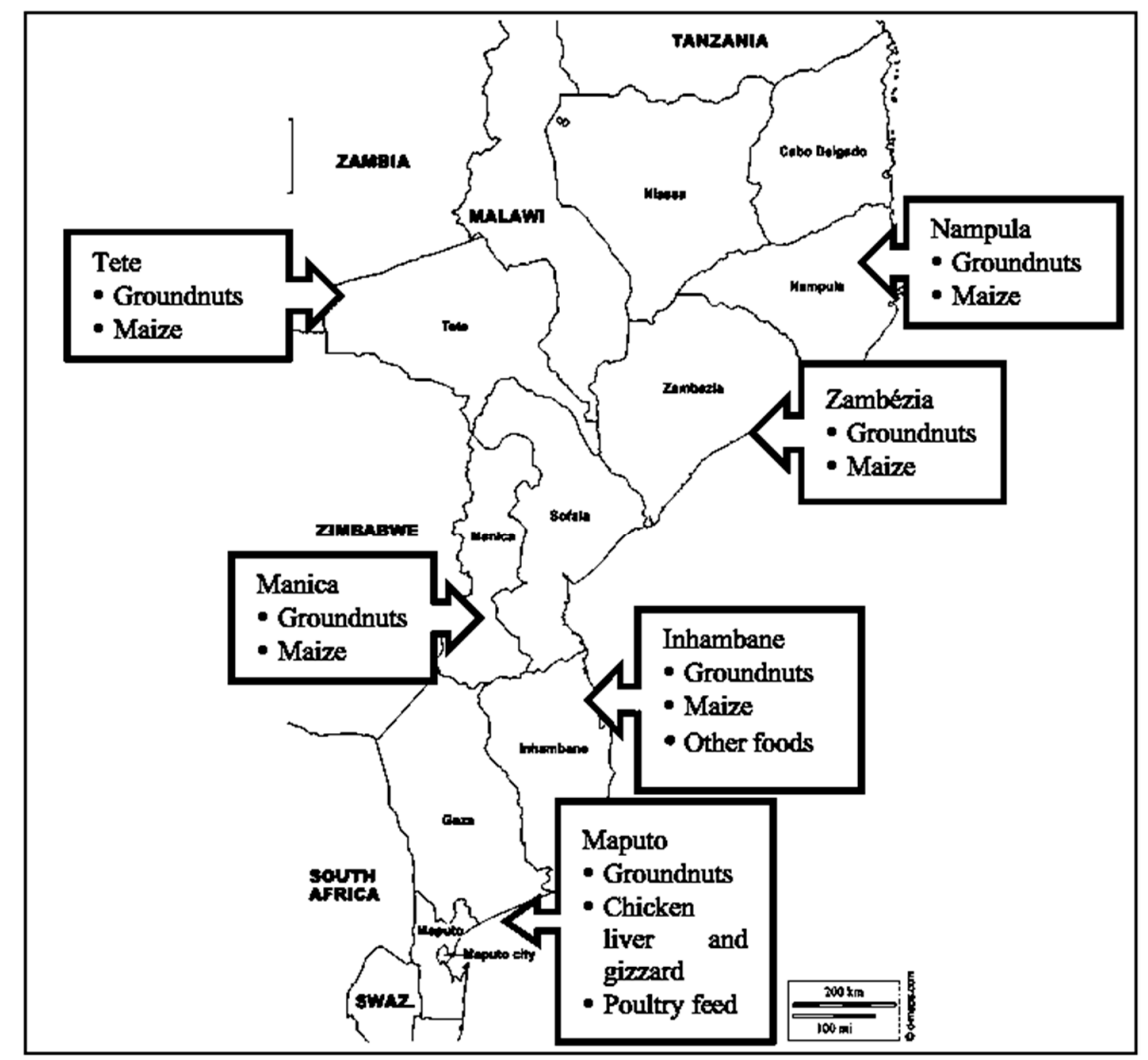

Figure 4. Mozambican provinces where aflatoxins have been detected and the products analyzed. Adapted from D-Maps [31] with data from Casadei [6], Van Rensburg et al. [7], van Wyk et al. [1], Warth et al. [2] and Sineque et al. [8]. These studies were carried from 1985 to 2017 and included in total 934 samples including agricultural crops, chicken livers and gizzards.

Casadei [6] found aflatoxins in samples from different areas of Mozambique, though he did not say which regions in his publication. Van Rensburg et al. [7] detected the toxins in samples from 
Inhambane. Augusto et al. [10] found in Manica, Zambézia, Tete and Nampula. Indeed, most of the recent studies were conducted in Nampula $[1,2,5]$. In this province, the highest toxin levels were noted in Mugovola, Erati, Amendo and Murrupia districts. Some of the reasons behind the choice of Nampula are its potential as a major producer of groundnuts and other cash crops, its proximity to Nacala Port, a strategic point of contact with the Indian Ocean markets, and its importance as the country's third biggest urban concentration if Maputo and Matola are taken as a single urban continuum [32]. Finally, groundnut, feed and animal studies suggest the existence of contaminated samples in Maputo City and areas in the proximity $[8,20,33]$. There is a need to address in the remaining provinces: Gaza, Sofala, Cabo Delgado and Niassa. These areas are certainly also affected by aflatoxin contamination.

Regarding primary hepatic cancer, Van Rensburg et al. [7] said Mozambique had high incidence by world standards but not so if compared to other African and Asian countries. Still, the country held the highest prevalence in Southern Africa [34], although it was decreasing [7], it is difficult to compare the data from Mozambique with other countries as Van Rensburg et al. [7] stated there are many local discrepancies, even among neighboring districts. They found contaminated food in all districts from Inhambane province but Govuro and Vilanculuos, and Manhiça and Magude in Maputo province. Yet, the incidence is low considering the aflatoxin levels found locally. Actually, the toxin seems to simply boost the HBV power to cause HCC. Casadei [6] added that liver cancer affected annually, per 100,000 inhabitants, 21 people in rural areas and 17 in the cities. He said a survey in the Central Hospital of Maputo showed 28 people for each 100,000 inhabitants. Previously, Van Rensburg et al. [35] described such levels as 100 times higher than the ones from western countries. Still, it does not clarify at which extent it was influenced by aflatoxin intake.

It is possible to see more details about the spatial distribution of aflatoxin contamination (Figure 5). The highest prevalence was found in Nacala, followed by Maputo City. Both are major commercial areas in Mozambique, where many products are imported and exported. If the products were purchased there, they might have been derived from the surrounding districts. Yet, it does not make the exposure any lower in these areas. Excluding Maputo, the top four areas with the highest prevalence are in Nampula province.

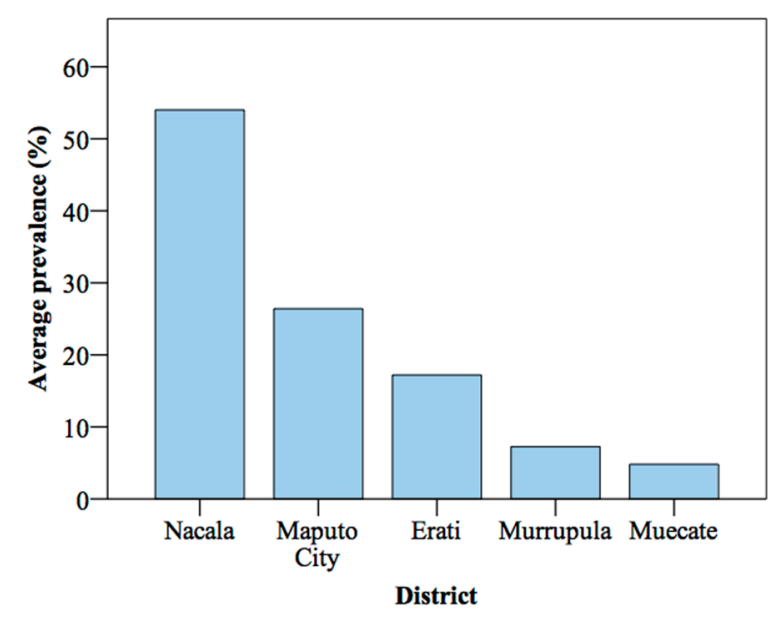

Figure 5. The districts with highest aflatoxin prevalence. Based on Casadei [6], Van Rensburg et al. [7], van Wyk et al. [1], Warth et al. [2] and Sineque et al. [8]. These studies were carried from 1985 to 2017 and included in total 934 samples including agricultural crops, chicken livers and gizzards.

The situation might be more complex and this data biased. Nampula is also the province with the highest volume of recent research on the matter. Its data is more discriminated and detailed if compared to any other province. Also, one of the foremost features mentioned by Van Rensburg et al. [7] was the variation between neighboring areas. Thus, observations from a few districts in a province might not be a fair representation of what is happening in the others. 
Districts with the highest aflatoxin levels (Figure 6) have records of extreme values if compared with the recommendation by the Codex Alimentarius [9].

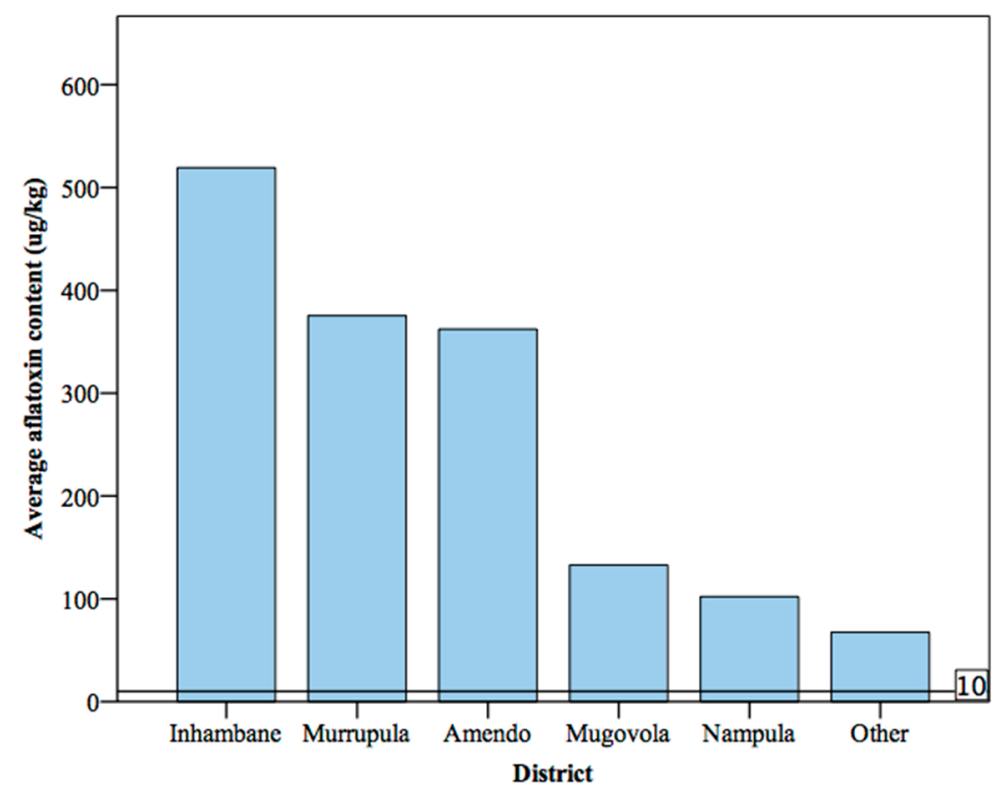

Figure 6. The districts with the highest aflatoxin levels in their foods. The horizontal line crossing the bars and the number at the right corner represent the maximum limit for peanuts $(10 \mu \mathrm{g} / \mathrm{kg})$ recommended by the Codex Alimentarius Commission [9]. Based on Casadei [6], Van Rensburg et al. [7], van Wyk et al. [1], Warth et al. [2] and Sineque et al. [8]. These studies were carried from 1985 to 2017 and included in total 934 samples including agricultural crops, chicken livers and gizzards.

Inhambane showed the highest values, followed by districts of Nampula province. As it seems, the first province leads in amount of toxin per food and the second in how spatially spread it is. Anyway, both appear to be hotspots of contamination, probably also with Zambézia [10].

\subsection{Susceptible Groups}

Most research is focused on commercial food. Thus, many people are susceptible to intoxication. The true level of exposure and impact of aflatoxin intake is not clear in Mozambique. Recent information covers very few commodities, lacks information on the frequency and quantity consumed and the physiological effect in the population. For example, the exposure of the population in Inhambane should result in a higher incidence of HCC [7], in theory.

So, there must be some resistance to aflatoxin exposure. For this reason, it is safer to look at susceptible groups by profiling the known cases of HCC. Furthermore, this review will not cover acute aflatoxicosis, as there is no scholarly information readily available about it in Mozambique.

Linsell and Peers [36] mentioned 101 cases of liver cancer in 576,782 individuals daily exposed to aflatoxin in their diets. This was the source from which Casadei [6] took the information for his book, then simplifying to make it more comprehensive. Most authors discussing the subject used directly or not the same article. Van Rensburg et al. [7] added by saying that this disorder was more common among adolescents and young adults, particularly male. According to Shephard [34], the incidence in males was 79.4 per 100,000. However, as the population aged, the sex ratio changed. Van Rensburg et al. [7] said this change is widespread in other parts of the world.

Again, the data above are old but are the best available. The high incidence in male adolescent and young adults was probably due to their behavior and relatively high mobility if compared to the female counterparts. It makes them more susceptible to venereal diseases including hepatitis B. It also gives them less control over their diet, eating what is available wherever they go. As time passes, 
they tend to settle, becoming more sedentary, responsible and creating families. This explains why the sex ratio of HCC changes, as they grow old.

\section{Detection, Prevention and Control}

\subsection{Detection Methods}

Chromatography is the most frequently mentioned method for aflatoxin analysis in Mozambique since the early studies (Figure 7). Van Rensburg et al. [7] used thin-layer chromatography (TLC) when correlating toxin contamination in food with consumer's liver cancer.

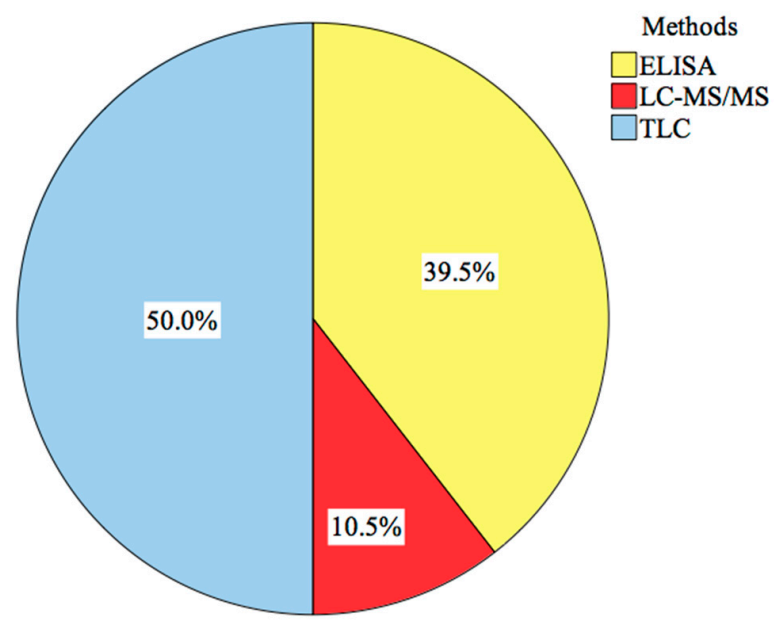

Figure 7. Usage of the most commonly analytic methods to detect aflatoxins in Mozambique. It counts every single measurement made by Casadei [6], Van Rensburg et al. [7], van Wyk et al. [1], Warth et al. [2] and Sineque et al. [8]. These studies were carried from 1985 to 2017 and included in total 934 samples including agricultural crops, chicken livers and gizzards.

Mondlane et al. [20] used the same method to detect AFB1 in poultry feed. Essers and Nout [16] used high-performance thin-layer chromatography (HPTLC) for cassava but their results were inconclusive, possible due to scopoletin interference. Warth et al. [2] recurred to liquid chromatography-tandem mass spectrometry (LC-MS/MS) to quantify mycotoxins in samples from Mozambique and Burkina-Faso. Anjos et al. [22] analyzed feed for chicks through high-performance liquid chromatography (HPLC). Harmsen et al. [4] recommended the latter method for the new laboratory of the Tertiary Polytechnic Institute of Manica.

Another method was enzyme-linked immunosorbent assay (ELISA). Actually, this is probably the most common but not for academic purposes. It is highly convenient for screening, especially when there is no need for quantitative measurements. Sineque et al. [8] used this method to detect $\mathrm{AFB}_{1}$ in chicken livers and gizzards. They recommended it as considerably rapid and economic technique for monitoring. Their suggestion was for feed and animal products but it is certainly good for many other types of commodities. However, they also said the method still required some improvements to guarantee more accurate results.

After using LC-MS/MS, Warth et al. [2] praised the method, describing it as powerful because it can analyze up to 28 different mycotoxins in a single sample. This machine can be a valuable asset for Mozambique, because very little is known about other mycotoxin in its food or feed, but the authors could detect several of them in samples from Nampula.

All methods have strengths and weaknesses. They can be costly and most require top-of-the-art equipment and trained personnel to operate [4]. Yet, investing in them can play an important part in the improvement of the public health. 


\subsection{Prevention}

This topic is poorly explored in Mozambique, despite of its vital relevance. Yet, there are some recommendations to both minimize aflatoxin exposure and the risk of liver cancer. Few will be presented here but the best idea for future researchers and professionals in this country is to search for the large volume of worldwide literature because most techniques suggested everywhere else are likely to also work in Mozambique.

For groundnuts, Zuza et al. [5] recommend the proper post-harvest management of groundnuts without delaying the harvesting time. This line of research was not new $[37,38]$ but it was a good initiative to reproduce in the Mozambican context to see what would happen. Harmsen et al. [4] commented on the storage techniques, suggesting jutting bags rather than plastic. Their recommendation was not straight out of the experiment; instead it was simply a commentary in a report about a new academic laboratory in Manica province. Yet, his expert opinion shall be accounted. There is some scholarly literature on the subject [39,40] and it is a good idea to study that in Mozambique.

Regarding liver cancer, Van Rensburg et al. [7] discussed the dual impact from both aflatoxins and HBV. They said preventive measures for aflatoxin exposure should be integrated with hepatitis $B$ vaccination to better alleviate the risk of cancer. However, if the measures were adopted, the results were never shared in public.

\subsection{Control}

In his paper, Casadei [6], Van Rensburg et al. [7], van Wyk et al. [1], Warth et al. [2] and Sineque et al. [8] recommended Mozambican authorities to follow the steps from the international counterparts. So far, several professionals and institutions have directly or indirectly driven their efforts to improve public health and food safety over the years. There is still a lot to be done but at least such endeavors, were in the right direction and can be taken as the foundation for very effective campaigns towards the reduction of aflatoxin contamination in Mozambique.

The Institute for Agricultural Research (IIAM), in Maputo City, rehabilitated its laboratory for food analysis and initiated a general survey. It aimed to start a surveillance program for hepatic cancer in Mozambique [6]. Such task would target the all steps of the food production chain, from farms to markets. At that time, the common food processing steps, including selection of non-infested seeds, were reported to reduce the aflatoxin contamination by around $70 \%$. However, there is a lack of recent information on the matter or even if there were further surveys.

The International Institute of Tropical Agriculture has actively been working in several African countries to minimize aflatoxin contamination through bio-control [41]. The institution's strategy was to develop a product based on endemic non-toxigenic strains of Aspergillus (branded as Aflasafe ${ }^{\circledR}$ ) able to compete with the toxigenic counterparts, reducing considerably the population. The product was effective in Nigeria and Kenya [41], and recently it has been introduced in Zambia and Mozambique [17]. The project also includes a campaign to sensitize the population and provide advice to the local policy makers.

Bentonite clay's adsorbent properties have been explored as an alternative aflatoxin control method for animals. Anjos et al. [22] found it to reduce the poisonous effect of aflatoxins in poultry feedstuff. However, it probably needs additional research because it was only partially effective. Once this method is fully developed, it can be easily adopted because the adsorbent is very abundant in the country.

\section{Recommendations}

Knowledge is needed for an effective aflatoxin control [17]. As there are limited resources for research, emerging economies like Mozambique can start by observing the progress in other places [1]. For example, various guidelines for farmers and other stakeholders are virtually applicable anywhere. 
Regarding harvest, time of the crop's physiological maturity is ideal to ensure minimum contamination [5]. However, it helps but does not necessarily address the problem. It is important to adopt an integrated pest management system. For instance, further stages such as storage also require attention because Aspergillus keeps growing if the temperature and humidity allow [21].

Since some areas in Mozambique, such as Inhambane, Nampula e Zambézia are known hotspot areas, the current efforts for research and intervention should be more focused in these areas [10]. This is actually happening already in Nampula, but very little is said about the other provinces. Since Nampula and Zambézia are neighbors, it would be just a matter to extend the effort invested in the former to the latter.

It is important to evaluate the cost-benefits of each detection method prior to introduction in Mozambique. Harmsen et al. [4] mentioned some skepticism from the authorities to purchase HPLC to the laboratory of soil analysis in the Tertiary Polytechnic Institute of Manica. They said similar equipment was being scarcely used in Nampula and it would be a good idea to invest in something more affordable such as ELISA. Indeed, Sineque et al. [8] used ELISA effectively and recommended routine screening. Still, they said the method had some limitations and their observations could not be conclusive without a more reliable method to validate their approach.

Funding: This research was funded by The Japanese Ministry of Education, Culture, Sports, Science and Technology (MEXT) for the financial support.

Conflicts of Interest: The authors declare no conflict of interest

\section{References}

1. Van Wyk, P.; Van der Merwe, P.; Subrahmanyam, P.; Boughton, D. Aflatoxin contamination of groundnuts in mozambique. Int. Arachis Newsl. 1999, 19, 25-27.

2. Warth, B.; Parich, A.; Atehnkeng, J.; Bandyopadhyay, R.; Schuhmacher, R.; Sulyok, M.; Krska, R. Quantitation of mycotoxins in food and feed from burkina faso and mozambique using a modern lc-ms/ms multitoxin method. J. Agric. Food Chem. 2012, 60, 9352-9363. [CrossRef] [PubMed]

3. Ferrão, J.; Bell, V.; Fernandes, T.H. Mycotoxins, food safety and security in sub-saharan africa. SM J. Food Nutr. Disord. 2017, 3, 1-9.

4. Harmsen, J.; Bremmer, J.; Maria, R.M. Pre Evaluation of a Soil and Plant Laboratory in Mozambique; Alterra: Wageningen, The Netherlands, 2012; p. 60.

5. Zuza, E.; Mondjana, A.; Muitia, A.; Amane, M. Effects of harvesting date on aflatoxin contamination in groundnuts in northern mozambique. In The Fifth RUFORUM Biennial Conference and African Higher Education Week; Nampala, M.P., Egeru, A., Tusiime, G., Osiru, M., Mensah, S., Adipala, E., Eds.; Regional Universities Forum for Capacity Building in Agriculture (RUFORUM): Cape Town, South Africa, 2016; Volume 14, pp. 167-172.

6. Casadei, E. Os contaminantes nos alimentos. In Mocambique: Águas, Alimentos e Ambiente; Molisv: Rome, Italy, 1980.

7. Van Rensburg, S.J.; Cook-Mozaffari, P.; Van Schalkwyk, D.J.; Van der Watt, J.J.; Vincent, T.J.; Purchase, I.F. Hepatocellular carcinoma and dietary aflatoxin in mozambique and transkei. Br. J. Cancer 1985, 51, 713-726. [CrossRef] [PubMed]

8. Sineque, A.R.; Macuamule, C.L.; Dos Anjos, F.R. Aflatoxin b1 contamination in chicken livers and gizzards from industrial and small abattoirs, measured by elisa technique in maputo, mozambique. Int. J. Environ. Res. Public Health 2017, 14, 951. [CrossRef] [PubMed]

9. Codex Alimentarius Commission. Codex General Standard for Contaminants and Toxins in Food and Feed; Codex Stan 193, 1995; Codex Alimentarius Commission: Omaha, NE, USA, 2013.

10. Augusto, J.; Atehnkeng, J.; Akello, J.; Cotty, P.; Bandyopadhyay, R. Prevalence and distribution of aspergillus section flavi in maize and groundnut fields and aflatoxin contamination in mozambique. In Proceedings of the 2014 APS-CPS Joint Meeting, Minneapolis, MN, USA, 9-13 August 2014; The American Phytopathological Society: Minneapolis, MN, USA, 2014. 
11. Baquete, E.; Freire, M. Present Status and Perspectives of Aflatoxin Research in Mozambique. Aflatoxin Contam. Groundn. 1989, pp. 93-94. Available online: http:/ / oar.icrisat.org/502/1/RA_00132.pdf\#page=263 (accessed on 10 May 2005).

12. Abbas, H.; Zablotowicz, R.; Locke, M. Spatial variability of aspergillus flavus soil populations under different crops and corn grain colonization and aflatoxins. Can. J. Bot. 2004, 82, 1768-1775. [CrossRef]

13. Andrade, P.D.; Caldas, E.D. Aflatoxins in cereals: Worldwide occurrence and dietary risk assessment. World Mycotoxin J. 2015, 8, 415-431. [CrossRef]

14. Liu, Z.; Gao, J.; Yu, J. Aflatoxins in stored maize and rice grains in liaoning province, China. J. Stored Prod. Res. 2006, 42, 468-479. [CrossRef]

15. Mota, T.P.; Lourenço, M.C. A farinha de mandioca de moçambique. Agronomia Mocambicana 1974, 8, 47-59.

16. Essers, A.A.; Nout, M.R. The safety of dark, moulded cassava flour compared with white-a comparison of traditionally dried cassava pieces in north-east mozambique. J. Food Technol. Afr. 2000, 5, 19-21. [CrossRef]

17. Bandyopadhyay, R.; Dubois, T. Aflatoxin control projects launched in southern Africa. In IIAPPS Newsletter; 2012; pp. 2-4.

18. Mussagy, I.H.; Babatunde, M.A. Government Spending on Education and Economic Growth in Mozambique: A cointegration Approach. Revista Electrónica de Investigação e Desenvolvimento. 2015, pp. 1-18. Available online: http:/ / reid.ucm.ac.mz/index.php/reid/article/view/68/84 (accessed on 12 May 2005).

19. Chiona, M.; Ntawuruhunga, P.; Benesi, I.; Matumba, L.; Moyo, C. Aflatoxins contamination in processed cassava in malawi and zambia. Afr. J. Food Agric. Nutr. Dev. 2014, 14, 3.

20. Mondlane, I.A.P.; Capece, B.P.S.; Parruque, A.F. Relação Entre a Ocorrência de Fungos e a Presença de Aflatoxinas b1 em Rações para aves Fabricadas em Maputo; Instituto de Investigação Agrária de Moçambique: Maputo, Mozambique, 2005.

21. Walker, T.; Pitoro, R.; Tomo, A.; Sitoe, I.; Salência, C.; Mahanzule, R.; Donovan, C.; Mazuze, F. Priority Setting for Public-Sector Agricultural Research in Mozambique with the National Agricultural Survey Data; Directorate of Training, Documentation, and Technology Transfer, Institute of Agricultural Research of Mozambique: Maputo, Mozambique, 2006; p. 80.

22. Anjos, F.D.; Ledoux, D.; Rottinghaus, G.; Chimonyo, M. Efficacy of mozambican bentonite and diatomaceous earth in reducing the toxic effects of aflatoxins in chicks. World Mycotoxin J. 2016, 9, 63-72. [CrossRef]

23. Carlson, M.P.; Ensley, S.M. Sampling and Analyzing Feed for Fungal (Mold) Toxins (Mycotoxins); Cooperative Extension, Institute of Agriculture and Natural Resources, University of Nebraska-Lincoln: Lincoln, NE, USA, 2003.

24. Guo, B.; Sobolev, V.; Holbrook, C.; Lynch, R. Impact of phytoalexins and lesser cornstalk borer damage on resistance to aflatoxin contamination. In American Peanut Research and Education Society Proceedings; American Peanut Research and Education Society: Tifton, GA, USA, 2004.

25. Sachs, J.D.; McArthur, J.W. The millennium project: A plan for meeting the millennium development goals. Lancet 2005, 365, 347-353. [CrossRef]

26. Griggs, D.; Stafford-Smith, M.; Gaffney, O.; Rockström, J.; Öhman, M.C.; Shyamsundar, P.; Steffen, W.; Glaser, G.; Kanie, N.; Noble, I. Policy: Sustainable development goals for people and planet. Nature 2013, 495, 305. [CrossRef] [PubMed]

27. Stevens, A.; Saunders, C.; Spence, J.; Newham, A. Investigations into "diseases" of turkey poults. Vet. Rec. 1960, 72, 627-628.

28. Ozturk, M. P53 mutation in hepatocellular carcinoma after aflatoxin exposure. Lancet 1991, 338, $1356-1359$. [PubMed]

29. Strosnider, H.; Azziz-Baumgartner, E.; Banziger, M.; Bhat, R.V.; Breiman, R.; Brune, M.N.; DeCock, K.; Dilley, A.; Groopman, J.; Hell, K.; et al. Workgroup report: Public health strategies for reducing aflatoxin exposure in developing countries. Environ. Health Perspect. 2006, 114, 1898-1903. [CrossRef] [PubMed]

30. International Agency for Research on Cancer (IARC). Aflatoxins. In IARC Monographs on the Evaluation of Carcinogenic Risks to Humans; IARC: Lyon, France, 2002; Volume 82, pp. 171-300.

31. D-Maps. Mozambique/República de Moçambique: Boundaries, Provinces, Names (White). Available online: http:/ / d-maps.com/carte.php?num_car=3537\&lang=en (accessed on 15 May 2018).

32. Mendonça, I.N.D. Urban mobility in maputo metropolitan area: Analysis of the management bodies of urban planning and mobility, institutional arrangements and inputs for effective articulation. J. Transp. Lit. 2014, 8, 244-270. [CrossRef] 
33. Arias, F.J.; Libombo, M. Groundnut evaluation in mozambique: Preliminary results for the 1993/94 season in maputo province. In Sustainable Groundnut Production in Southern and Eastern Africa, Proceedings of a Workshop, Mbabane, Swaziland, 5-7 July 1994; Ndunguru, B.J., Hildebrand, G.L., Subrahmanyam, P., Eds.; International Crops Research Institute for the Semi-Arid Tropics: Mbabane, Swaziland, 1994.

34. Shephard, G.S. Risk assessment of aflatoxins in food in africa. Food Addit. Contam. Part A Chem. Anal. Control Expo. Risk Assess. 2008, 25, 1246-1256. [CrossRef] [PubMed]

35. Van Rensburg, S.J.; Kirsipuu, A.; Coutinho, L.P.; Van Der Watt, J.J. Circumstances associated with the contamination of food by aflatoxin in a high primary liver cancer area. S. Afr. Med. J. 1975, 49, 877-883. [PubMed]

36. Linsell, C.A.; Peers, F.G. Aflatoxin and liver cell cancer. Trans. R. Soc. Trop. Med. Hyg. 1977, 71, 471-473. [CrossRef]

37. Kaaya, A.N.; Warren, H.L.; Kyamanywa, S.; Kyamuhangire, W. The effect of delayed harvest on moisture content, insect damage, moulds and aflatoxin contamination of maize in mayuge district of uganda. J. Sci. Food Agric. 2005, 85, 2595-2599. [CrossRef]

38. Jones, R.; Duncan, H.; Hamilton, P. Planting date, harvest date, and irrigation effects on infection and aflatoxin production by aspergillus flavus in field corn. Development 1981, 19, 32.

39. Bulaong, S.S. Fungal population, aflatoxin and free fatty acid contents of peanuts packed in different bag types. BIOTROPIA Southeast Asian J. Trop. Biol. 2002. [CrossRef]

40. Essono, G.; Ayodele, M.; Akoa, A.; Foko, J.; Filtenborg, O.; Olembo, S. Aflatoxin-producing aspergillus spp. And aflatoxin levels in stored cassava chips as affected by processing practices. Food Control 2009, 20, 648-654. [CrossRef]

41. Cardwell, K.; Cotty, P.; Bandyopadhyay, R.; Mutegi, C.; Nelson, F.; Marwa, M.; Manyong, V. Biocontrol for Aflatoxin; International Institute for Tropical Agriculture (IITA): Dar es Salaam, Tanzania, 2015; p. 50.

(C) 2018 by the authors. Licensee MDPI, Basel, Switzerland. This article is an open access article distributed under the terms and conditions of the Creative Commons Attribution (CC BY) license (http:/ / creativecommons.org/licenses/by/4.0/). 